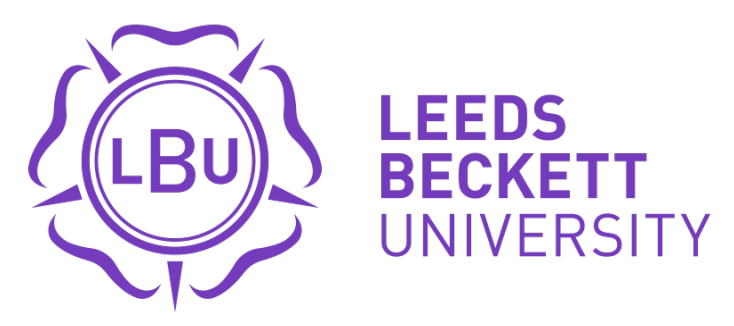

Citation:

Williams, TL (2018) Exploring narratives of physical activity and disability over time: A novel integrated qualitative methods approach. Psychology of Sport and Exercise, 37. pp. 224-234. ISSN 1469-0292 DOI: https://doi.org/10.1016/j.psychsport.2017.09.004

Link to Leeds Beckett Repository record:

https://eprints.leedsbeckett.ac.uk/id/eprint/4088/

Document Version:

Article (Accepted Version)

The aim of the Leeds Beckett Repository is to provide open access to our research, as required by funder policies and permitted by publishers and copyright law.

The Leeds Beckett repository holds a wide range of publications, each of which has been checked for copyright and the relevant embargo period has been applied by the Research Services team.

We operate on a standard take-down policy. If you are the author or publisher of an output and you would like it removed from the repository, please contact us and we will investigate on a case-by-case basis.

Each thesis in the repository has been cleared where necessary by the author for third party copyright. If you would like a thesis to be removed from the repository or believe there is an issue with copyright, please contact us on openaccess@leedsbeckett.ac.uk and we will investigate on a case-by-case basis. 


\title{
Exploring narratives of physical activity and disability over time: A novel integrated qualitative methods approach
}

\author{
Dr Toni L. Williams* \\ Institute for Sport, Physical Activity \& Leisure, Leeds Beckett University
}

*Address for corresponding author: Fairfax Hall 202, Headingley Campus, Leeds

Beckett University, Leeds, LS6 3QS, UK

$\underline{\text { T.L.Williams@ @eedsbeckett.ac.uk }}$

To cite this article:

Williams, T. L. (2017). Exploring narratives of physical activity and disability over time: A novel integrated qualitative methods approach. Psychology of Sport and Exercise. doi: 10.1016/j.psychsport.2017.09.004 


\begin{abstract}
Objectives: The fusion of multiple qualitative methods has the potential to provide a more multidimensional and nuanced understanding of sport and exercise participation for disabled populations. The purpose of this innovative methods paper was to illustrate the use of a longitudinal integrated methods approach to explore the storied experiences of activity-based rehabilitation (ABR) for people with spinal cord injury (SCI). Methods: A novel combination of interviews, timelining and participant observation was used with participants with SCI, and their trainers, at an ABR center in the UK. These pluralistic data sets were subject to a dialogical narrative analysis to identify: 1) the types of narratives that people drew upon to construct their stories of $\mathrm{ABR}$ and 2) the relationships between health, well-being and hope over time. Results: Two participants' stories were used to demonstrate how multiple data sets can help illuminate complementary and contrasting understandings of ABR. Critical reflections were also offered to highlight the rigorous and reflexive process of integration throughout the research process. Conclusions: The integration of multiple methods was successful in providing new and enriched insights of ABR that may not have been achieved through one method alone. Epistemological and theoretically informed multiple methods studies may have promise for similar psychological research projects exploring the complexity of sport and exercise experiences for disabled people. To conclude, recommendations and future directions for the use of integrated methods within sport and exercise psychology research are offered.
\end{abstract}

\title{
Keywords
}

Multiple methods; interviews; timelining; participant observation; activity based rehabilitation; spinal cord injury. 


\section{Introduction}

Activity-based rehabilitation ${ }^{1}(\mathrm{ABR})$ is a novel yet contentious community physical activity training program for people with neurological conditions such as spinal cord injury (SCI). Characterized by individual intensive exercise programs, the aim of $\mathrm{ABR}$ is to improve physiological, functional and neurological outcomes, and promote independence (see Jones et al., 2014; Quel de Oliveira et al., 2017). At the same time, through regular exercise, ABR has the potential to improve health and well-being and thereby enrich quality of life (Papathomas et al., 2015; Perrier et al., 2013). Furthermore, ABR centers provide people with SCI the opportunity to pay to exercise with the aid of specialist health professionals at a purpose built facility. These bespoke exercise opportunities are important as people with SCI are often prevented from leading a physically active lifestyle due to multiple personal, environmental and social barriers (Martin Ginis et al., 2016; Williams et al., 2014). In other words, people with SCI often experience disablism - a form of social oppression - when these disabling and discriminatory barriers impede their sport and exercise participation (Richardson et al., 2017; Smith et al., 2016; Thomas, 2014).

Despite the potential role of ABR in getting more people with SCI physically active, a number of concerns have been raised with this type of exercise. For example, some physiotherapists in SCI rehabilitation were reluctant to promote ABR as a viable physical activity option due to concerns over how hope is managed in this context (Williams et al., 2016). During SCI rehabilitation, physiotherapists are in a delicate position of fostering hopefulness for the future, without promoting false hope of recovery (Soundy et al., 2010; van Lit \& Kayes, 2014). To achieve this balance, the goals of rehabilitation are focused upon teaching people with SCI to live a meaningful and independent lifestyle which includes mastering activities of daily living (van Lit \& Kayes, 2014; Williams et al., 2016). In contrast, a primary goal of many ABR

\footnotetext{
${ }^{1}$ Activity based rehabilitation is also known as activity based therapy in North American and other contexts
} 
programs is to activate the neuromuscular system below the level of injury - through activities such as gait training and assisted walking - to facilitate the recovery of specific motor tasks (Sadowsky \& McDonald, 2009). Consequently, some physiotherapists perceive these goals of $\mathrm{ABR}$ to be problematic, and dangerous, as they foster unrealistic expectations and false hope of recovery from SCI (Williams et al., 2016).

Conversely, these concerns held by physiotherapists regarding ABR are not unfounded. For instance, a recent systematic review and meta-analysis by Quel de Oliveira et al. (2017) supported the use of ABR interventions to improve upper limb function, mobility and independence in areas of self-care and ability to reach and manipulate objects. However, the authors found that ABR had no effect on independence, mobility of lower limbs, and quality of life in comparison to conventional rehabilitation physical interventions, regardless of the level of injury to the spinal cord. These conventional physical interventions, typical of SCI rehabilitation, target regions above the level of injury aiming to compensate for loss of function. Such physical activities include muscle strengthening, task-specific training, activities of daily living and aerobic exercise. In light of these findings and the cost of ABR (e.g., expensive equipment and high staff intensity), the authors concluded that health professionals need to be mindful of promoting ABR over other physical activity options.

Equally, the qualitative literature exploring how people with SCI interpret their experiences and outcomes from participating in ABR also highlighted some cautionary remarks. Narrative studies by Perrier et al. (2013) and Papathomas et al. (2015) found that people with SCI perceived they gained both physical and psychological benefits from participating in ABR which positively impacted their quality of life. These studies also revealed that some people were motivated to participate in ABR in the hope of returning to a former able-bodied self. In narrative terms, the stories told by these participants were guided by the exercise is restitution narrative which projects a storyline of hope for recovery or cure following SCI through engaging in exercise (Papathomas et al., 2015). Critically, Perrier et al. (2013) warned that a 
pre-occupation with restitution may restrict individuals from partaking in other physical activity opportunities which may be psychologically fulfilling and supportive of exercise maintenance in the long term. Furthermore, Papathomas et al. (2015) highlighted that exercise is restitution is potentially psychologically dangerous due to the fragile inflexibility, and vulnerable long-term implications, of this story for people with SCI if recovery is not forthcoming.

Although the narrative studies by Perrier et al. (2013) and Papathomas et al. (2015) have shed some light on the experiences of ABR, the use of the single semi-structured interview within these studies has left some questions unanswered. For example, it is unknown as to when narratives such as restitution are told in relation to SCI and ABR, or how narratives of health, well-being and hope differ over time through sustained ABR participation. Furthermore, in light of the concerns regarding exercise is restitution, the long-term sustainability of living by this narrative needs to be explored. These empirical questions have significant implications for the promotion of ABR as a long term physical activity option for people with SCI. One way to address these questions and gain a more nuanced and multi-dimensional understanding of the storied experiences of ABR over time may be achieved through the use of integrated methods.

As outlined by Chamberlain et al. (2011), integrated methods are one type of pluralism in qualitative research where multiple qualitative methods are drawn upon across the research process. This fusion of qualitative methods has the potential to address the complexity of issues in social science by providing pluralistic data sets that offer 'different takes' on a topic and insights that are unlikely to appear through one method alone (Chamberlain et al., 2011; Lyons et al., 2015). Moreover, synthesizing more than one method provides the opportunity for a deep in-context interpretation incorporating chronological, spatial and corporeal understandings of the participants' lifeworld (Gibson et al., 2013; Papaloukas et al., 2017). Within sport and exercise psychology, qualitative research is dominated by the use of interviews as a method of data collection (Culver et al., 2012). The use of multiple methods to supplement interview data - 
and capture multi-dimensional and embodied understandings that may be inaccessible solely through verbal means - is underutilized with this field (Smith et al., 2015).

\section{Multiple methods qualitative research}

The use of multiple methods shares some areas of controversy with that of 'mixed methods' research (MMR). In contrast to multiple methods, MMR involves the combination of quantitative and qualitative methodologies and methods. One largely rehearsed debate concerns the conflicting underlying philosophical assumptions between these two research approaches (see McGannon \& Schweinbenz, 2011; Sparkes, 2015). As Chamberlain et al. (2011) contend, "the use of multiple qualitative methods should not give rise to clashes of ontology or epistemology because these should be aligned with the research objectives" (p.153). However, other areas of contention such as the integration of methods and findings does ring true for multiple methods research. This fundamental issue raises questions such as what is meant by integration? How is this done? Where is it done? How are the different data sets mutually illuminating? How are contradictory findings dealt with? (Creswell, 2011; Sparkes, 2015).

An essential component of MMR is that the different methods, analyses and findings talk to each other to construct an overall account whereby the end product becomes greater than the sum of its parts (Creswell, 2011, Sparkes, 2015). Similarly, in multiple methods research, a crucial component is the fusion of the separate methods into an integrated research process. For example, Chamberlain et al. (2011) propose that researchers should not succumb to the temptation to undertake the analysis and presentation of the various forms of data separately. Rather, the analysis should extend across the pluralistic data sets to provide integrated meanings. Without this level of integration there is little 'value added' to our understanding of a phenomena beyond the individual components of a study (Creswell, 2011). To achieve this level of integration in a multiple methods project demands a high level of reflexivity to question, examine and reflect upon the research process as a whole (Chamberlain et al., 2011; Smith et al., 2015). In line with MMR, this integration of multiple methods may include comparing and 
contrasting data, as well as building upon and embedding one argument within another (Creswell, 2011).

Some noteworthy contributions have been made to the disability sport and exercise psychology literature through the use of multiple methods research. For instance, Smith et al. (2016) examined the complex issue of activist identities among disabled elite athletes through the use of interviews, fieldwork observations and social media material. Yet there was no detail provided of how the pluralistic data sets were integrated, or if there were any contrasting or conflicting findings between the 'telling' of identities in interviews, the 'performing' of identities in observations or the 'display' of identities in social media accounts. In another example, Richardson et al. (2017) utilized the methods of video conferencing and mobile methods to investigate the gym as a potential place to promote health for disabled people. However, within the presentation of results, and the discussion of findings, no further insights were offered as to how the different interview methods influenced the data analysis and results to produce an end product greater than one interview method alone.

Emphasizing that such authors do not detail the integration of multiple methods is not to be critical of their scholarship. Rather, it illustrates the challenges of demonstrating integration and the absence of such discussions within the literature. This issue is further compounded by tight word counts in journals that do not afford authors the space to explain and justify the integration of methods (Chamberlain et al., 2011). In light of this, the purpose of this innovative methods paper was to develop an integrated approach to explore the storied experiences of $A B R$ and achieve a more nuanced understanding of the relationship between health, well-being and hope over time. In what follows, I outline the study details and provide a rationale for combining interviews, timelines, participant observation and reflexive journal notes within a narrative approach. I then present two examples to illustrate how the integration of methods led to new and enriched insights of the experiences of ABR for people with SCI. Throughout these examples I reflect critically upon my experience of the process of integration through the 
collection, analysis and interpretation of multiple data sets. Lastly, I conclude by providing recommendations and future directions for the use of integrated qualitative methods within sport and exercise psychology research.

\section{Methodology}

\section{A narrative approach}

Narrative inquiry was chosen as the broad underpinning methodology as it offered numerous advantages to the research process. First, a focus on stories is important because they are a key means by which people make sense of their lives following serious injury such as SCI (Frank, 2013). Second, through a narrative lens there is a strong emphasis on human lives being culturally and relationally constructed (Riessman, 2008; Smith, 2016). Therefore this allowed me to focus upon the personal stories of participants whilst also exploring how these stories were shaped by narrative resources circulating within and beyond this context (Gubrium \& Holstein, 2009). Third, unlike other methods of analysis, narrative focuses on both the whats (e.g., what is the story about) and the hows (e.g., how is the story structured) of talk (Gubrium \& Holstein, 2009). A fourth advantage of narrative inquiry is that it enabled me to explore how participants understood their experiences of SCI and ABR in relation to their biographical history and chart their lives over time (Sparkes \& Smith, 2014). In line with these characteristics, narrative inquiry falls within an interpretivist paradigm, framed by ontological relativism (which assumes reality to be multiple, malleable and subjective) and epistemological social constructionism (which assumes knowledge is socially constructed through relational interactions) (Papathomas, 2016).

\section{Sampling and participants}

Following university ethical approval, a purposive criterion-based sampling strategy (Sparkes \& Smith, 2014) was used to recruit participants with SCI who were partaking in ABR at a center in the UK. Due to the variability of clients to the ABR center in terms of age and time since injury, any clients who were over the age of 18 and had acquired their SCI were permitted to take part. 
Initial contact was made with the participants via email from the trainers at the ABR center outlining details of the study. The trainers also discussed the research project with their clients during their ABR sessions. If anyone was interested in taking part, I provided them with an introductory participant information sheet and answered any questions they had.

In total, 10 participants with SCI took part in the study. Reflecting the higher incidence of SCI in men compared to women (McCaughey et al., 2016; World Health Organization, 2017), 8 participants were male and 2 were female. The participants varied in terms of their age (20-52 years), time since injury (1-28 years), level of injury (including complete and incomplete SCI) and cause of injury (e.g, fall from height, road traffic accident, violence). All participants had been participating in the ABR program between 1 month and 2.5 years at the start of the study. In addition to the clients of the ABR center, the 5 trainers and one of the directors also agreed to take part in the study to enable me to understand their views and experiences of ABR. The trainers were all aged between 25 and 30 years' old, and had 2 to 7 years' experience working in ABR. They were all from a sports science background including sports therapy and personal training, and one had over five years' prior experience at an ABR center in North America.

\section{Data collection}

To gain a longitudinal perspective of experiences of ABR, the data collection period spanned 18 months. Prior to commencing any data collection, all participants and their family members were provided with information about the study and informed consent was gained.

\section{Interviews}

All participants with SCI were involved in a semi-structured life-history interview to explore their lifestyle before SCI, life with SCI, the role of physical activity in their rehabilitation and their experiences of ABR. The use of semi-structured interviewing allowed for pre-planned questions to guide the conversation, but invited participants to tell stories about their experiences, feelings and behaviors in relation to SCI and ABR (Sparkes \& Smith, 2014). In line 
with a longitudinal qualitative design, these participants were then interviewed a second time, approximately one year later. The aim of longitudinal qualitative interviews is to pose "different questions on selected same and newly emergent themes" to examine change over time (Hermanowicz, 2013, p.198). In the second interview I asked participants to elaborate on their experiences of $\mathrm{ABR}$ over the last year and took this opportunity to seek clarification and elaboration of any responses from the first interview. To elicit narrative data and the telling of stories, participants were encouraged to 'tell me a story that represents your overall experience of ABR?' Each of the five trainers and one director were interviewed once to enable them to share their experiences of developing and delivering ABR programs for people with SCI. All data were transcribed verbatim and each participant was given a pseudonym.

\section{Timelining}

Timelining is a form of graphic elicitation that visually represents how participants make sense of experience over time. Here the participant and/or researcher draws a temporal graph and plots the critical incidents that either positively and/or negatively impact an experience as it unfolds (Sheridan et al., 2011; Sparkes \& Smith, 2014). This focus on time and temporality is a distinguishing feature of timelining (Phoenix \& Rich, 2016) and a defining characteristic of stories and narrative (Brockmeier, 2000; Riessman, 2008). As Sheridan et al. (2011) comment, "time and narrative are inextricably woven together, in that narrative almost always involves time and requires a temporal component to be meaningful” (p. 554). In practice, timelines have the potential to build rapport during interviews, facilitate a sense of comfort and actively engage participants through reflection of life events (Kolar et al., 2015). Thus in this project, the use of timelining was to support interviews and encourage participants to tell stories about their experiences of ABR outside of the boundaries set by language alone (Phoenix \& Rich, 2016).

During the second interview, each participant with SCI, with help from myself where necessary, constructed a timeline on an A4 size sheet. Time in years was plotted on the horizontal axis and positive (above the horizontal axis) and negative (below the horizontal axis) 
perceptions of health, well-being and hope were plotted on the vertical axis. These axes provided a scaffold for the participants to plot their experiences of health, well-being and hope over time. In this instance health was plotted as perceived physical health $(\mathrm{PH})$, well-being was plotted as perceived mental health ${ }^{2}(\mathrm{MH})$ and hopes reflected the participants' hope and expectations either at that moment in time, or for the future. Participants were able to choose the extent of the time frame and these ranged from one year (time in-between interviews) to 4 years (from the onset of SCI).

\section{Participant observation}

To complement the storied experiences constructed through interviews, I also collected observational data at the ABR center. Participant observation is one method that enables the researcher to explore both what is said in interviews and what is done in practice (Sparkes \& Smith, 2014; Thorpe \& Olive, 2016). Furthermore, observational methods enable the examination of peoples' lives in real time and "record the mundane, taken-for-granted, and unremarkable (to participants) features of everyday life that interviewees might not feel were worth commenting on" (Sparkes \& Smith, 2014, p.100). As Gubrium and Holstein (2009) contend, social reality explored through narrative inquiry does not need to stay within the boundaries of conversation: "it is imperative that in addition to what is said and recorded on any occasion, researchers go out into the world, observe and listen, and document narrative's everyday practices" (p.15). The combination of observational and interview data can therefore act as a resource for generating a more complex understanding of people's lives (Smith, 2013).

Observational methods permit a much lengthier and more involved engagement in the field and comprises the researcher spending time getting to know people, rather than just knowing about them (O'Reilly, 2012; Sparkes \& Smith, 2014). To achieve this aim, the researcher must participate (physically, cognitively, socially, sensually and /or emotionally) in

\footnotetext{
${ }^{2}$ The term 'mental health' was plotted on the timelines and discussed in interviews instead of 'well-being' as this was the language commonly used by participants.
} 
varying degrees in the lives and culture of the participants (Thorpe \& Olive, 2016). My role in the field was predominantly a participant as observer as I immersed myself in the daily activities of the ABR center over the 18 month period (one day every other week). Shortly following a period of participant observation, my thoughts and observations were recorded in detailed field notes. Field notes within observational settings often include, but are not limited to, what is going on, commenting on the people in the field, where and when social interactions take place and why this is happening (O'Reilly, 2012). During my immersion at ABR I was able to record and deliberate on the actions of the participants at ABR as they acted out elements of their stories in interactions of the gym floor. In addition to events that occurred during my interaction with participants, I observed and documented the interactions that took place on the gym floor or in the waiting area, the ways in which the trainers, participants and their family members interacted with each other, and the stories told in conversations throughout the day.

\section{Researcher reflexivity}

Throughout the study I kept a reflexive journal to focus close attention upon my own thoughts, feelings, actions, and question how my position with the field impacted the research process including the gathering, analysis and integration of data. For data collection, reflexivity is crucial to conducting quality observations as the researcher's experience of the culture, as well as their age, sex, ethnicity, sexuality and/or (dis)ability will influence the interactions, relationships and observations accessed, focused upon and ignored (Brighton \& Williams, inpress; Thorpe \& Olive, 2016). For example, my status as a young, non-disabled female, in a mostly male dominated environment did influence my behavior and interactions with participants on the gym floor (see reflections in Gareth's story). Furthermore, according to Wolcott (2005), such reflexivity involves disciplined subjectivity through attention to bias. To do this I tried to identify my own preconceptions about ABR, where these ideas had come from, and how I was going to address them within my observations and interpretations. In this instance, my preconceived ideas had arisen from the more positive stories told within the ABR 
center (from staff before data collection commenced) and the more skeptical stories told by physiotherapists in SCI rehabilitation (see Williams et al., 2016).

In addition to the stories I had heard concerning ABR, I also had first-hand experience of working with disabled people which impacted my perception within the field. For example, I was a carer for a number of years and also worked as a sports massage practitioner for various sports including the London 2012 Paralympic Games. These experiences facilitated my movement from 'outsider' to 'insider' fairly quickly within the ABR center as I soon acted as an 'assistant' to the trainers. Although the positioning of researchers as inside or outside of a group remains a contentious issue (see Thorpe \& Olive, 2016), this insider role enabled me to improve relationships and build trust and rapport with both the participants and the trainers. As part of this role I adopted an embodied and multi-sensual approach to data collection as I set up exercise equipment, helped transfer participants with SCI from their wheelchair to the plinth/floor and supported their body's as they exercised. Having a defined role within the ABR center was crucial in avoiding what others have described as a 'professional stalker' when doing nothing during observation (Sanders et al., 2017, p.3). That said, I was mindful of becoming overly familiar within the ABR center and tried to maintain a 'critical distance' to observe (and question) practices that might otherwise be taken for granted (Sparkes \& Smith, 2014; Thorpe \& Olive, 2016). My reflexive approach to data analysis and integration is discussed below.

\section{Dialogical narrative analysis}

Dialogical narrative analysis (DNA) was the analytical perspective used to make sense of the multiple forms of data. This method of narrative analysis is concerned with not only the story told by participants, but the work that stories do for and to people. As Frank (2010) contends, DNA "studies the mirroring between what is told in the story - the story's content - and what happens as a result of telling that story - its effects" (pp.71-72). Thus, through DNA, stories are examined for what is said, the narrative resources used to help structure storytelling, what stories do and the reasons why a person chooses to represent their life using a particular story 
(Smith, 2016). The method for carrying out a narrative analysis purposely lacks a prescribed set of steps that should be followed meticulously (Sparkes \& Smith, 2014). Indeed, Frank (2010) describes DNA as movement of thought that asks questions of the data in analysis. Therefore the method of DNA should be understood as a heuristic guide rather than a set of procedural and prescriptive guidelines. Moreover, as Smith (2016) suggest, "movement of thought can take the analyst in unexpected and fertile directions, breathing fresh life into moribund concepts, encouraging theoretical curiosity, and provoking new ways of seeing in the process" (p.12). Thus, the aim of adopting DNA as a heuristic guide and method of questioning was to spur imagination and inspiration that could lead to new insights and understanding of SCI and ABR.

Making sense of the multiple data sets through DNA involved various analytical stages. It was an iterative and cyclic process that began alongside data collection and continued throughout the writing up stage. The process began during data collection as I took notes of the stories that appeared to be emerging from my field notes and during transcription of the first interview with participants. This was the start of the period of indwelling. Indwelling further involved reading and re-reading interview transcripts alongside field notes to familiarize myself with the data and look for complementary and contradictory insights into experiences of ABR. Most of the participants were interviewed within the first couple of weeks of the data collection period which meant I had very few field notes regarding their participation in $A B R$ at that time. Therefore I began analyzing their first interview data before I had any observational data to compare with. For other participants it took a few months to arrange their first interview (due to illness, other commitments etc.) by which time I had already started analyzing the observational data (see Gareth's story). This stage involved (loosely) coding the data in the first interview transcripts and initial field notes with conceptual comments (Smith, 2016). I then drew upon the codes and conceptual comments from the interview and observational data to identify narrative themes and thematic relationships both within and across participants. 
In line with what Gubrium and Holstein (2009) refer to as analytical bracketing, the initial focus was on the content of the stories to address the whats of talk and answer questions such as 'What are the common themes or threads in the story?' and 'What meanings did participants assign to their experiences?'. Next, the content was bracketed and the DNA was expanded to "bring the storytelling back into the analysis" (Frank, 2010, p.105). This stage involved focusing upon how stories were put together and identifying the types of stories being told. Here I was trying to identify both individual stories (e.g., participants stories developed in the interview transcript) and the larger stories operating within the environment and culture at the ABR center that were noted during observation. To address the effects that these stories had on the participants, they were considered in light of a set of dialogical questions. Drawing upon Frank (2010), examples of dialogical questions included: resource questions (What narrative resources do the participants draw upon to shape their subjective experiences of SCI and PA?); identity questions (How do participants tell stories to explore whom they might become?); function questions (As 'actors', how do the participants' stories shape their actions?); and interpretation questions (What details may have been expected but were omitted?).

To explore these questions I drew upon writing as a form of analysis. As Sparkes and Smith (2014) explain, writing is not a 'mopping up' activity to be completed at the end of a research project. Rather, analysis happens in the process of writing because in doing so one can progressively discover ideas and recognize the actions of stories. Moreover, according to Frank (2011), "the research report is not post hoc to an analysis that is completed before writing. Rather, reports emerge in multiple drafts that progressively discover what is to be included and how those stories hang together" (p.43). My analysis of the stories told by participants about their experiences of ABR evolved gradually and progressively. The use of DNA initially allowed me to identify the thematic relationships and types of narrative that people were drawing upon to construct their experiences of ABR. To further identify patterns in stories over time, a variety of conceptual and thematic questions were also employed in the analysis of the 
later field notes, second interviews and timelines. These included: What increased/emerged over time? What decreased or ceased over time? What remained constant through time?

(Hermanowicz, 2013, p.190). Incorporating the use of timelining further illuminated the participants' interpretations of their health, well-being and hope across time as they participated in ABR. The timelines were examined for both their contribution to understanding ABR experiences, and how the use of timelining changed the interview process (Kolar et al., 2015; Sheridan et al., 2011).

To achieve the fusion of all data sets into integrated meanings, I compared the storied data from the first interview with that of the second interview and timeline, and drew upon the observational data and reflexive notes to support or contrast my interpretations of how stories of ABR unfolded over time. Examples of how the pluralistic data sets complemented and contradicted each other are provided in the results and discussion section below. Further detail on how I dealt with contrasting and contradicting data is reflected upon within the conclusion.

\section{Results and Discussion}

The use of DNA on these pluralistic data sets allowed me to identify the different types of narratives that people drew upon to construct their experiences of $\mathrm{ABR}$, and relationships between health, well-being and hope that may not have been revealed through the use of one method alone. In light of the purpose of this study, two exemplar stories from two participants are presented which illustrate how the integration of methods led to a more comprehensive and enriched understanding of experiences of ABR over time. These two stories were chosen as they were data rich cases that best demonstrated the analysis and interpretation of multiple methods in action. The first - Gareth's story - highlights how pluralist data sets can reveal the intricacies of participants' stories over time that might otherwise have been taken for granted. The second Robert's story - illustrates how the fusion of qualitative methods can lead to insights that helped contest the underlying assumptions of dominant narratives within this field.

\section{Gareth's story}


Gareth was 47 years old at the time of our first interview and had been attending ABR for one and a half years. He acquired a C4-C5 complete SCI after falling from a height three years prior. At this level of injury, Gareth was tetraplegic and had very limited movement in his neck, shoulders, arms and hands. At the outset of our first interview, Gareth told his story in light of his previous sporting achievements through his youth and into adulthood. In essence, he was initially motivated to exercise to continue, and return to, his previously embodied physically active and athletic identity (Williams et al., 2014). For Gareth, his participation in ABR was deeply rooted within the exercise is restitution narrative as his desire to restore his former ablebodied self, and the hope of walking again, motivated his sustained engagement in ABR:

Toni: Why did you decide to come to ABR?

Gareth: I enjoyed my life; I've done loads of things. I've jumped out of planes, I've been up mountains, I've scuba dived, I've played football, I did kickboxing, I've boxed, I used to swim for England and Great Britain in my youth. I could go on and on I've led quite the highlife... As I used to be quite physical, anything to do with going forwards suited me really. I'd give everything I had to try and get back up and get walking. It (ABR) gives me that incentive to carry on because I can only go up the ladder, I can't go down, I'm already at the bottom and I can only go up.

Toni: That's a positive way to look at it.

Gareth: I have to, don't I really you know. Otherwise I would...I never knew this but I used to sit out front of the care home and the nurses told the carers to keep an eye on me because it was just off the main road and they thought when I was upset I might drive in front of a car. But I've got to admit, the thought did cross my mind a few times when I got upset, but I would never do it because I've got to give it a chance. At the moment if people say to me you've got to accept it then I won't. I don't think I should accept it, there is always hope. If I didn't have that hope, I wouldn't want to carry on. $\left(1^{\text {st }}\right.$ interview) 
Gareth's story also alluded to the fragility of the exercise is restitution narrative. For Gareth, partaking in ABR was aimed at defying his SCI as he was challenging, rather than accepting, the limitations placed upon his by his SCI (Soundy et al., 2014). The concern with a seeming stable commitment to exercise through restitution is that these stories are told on the edge of chaos (Papathomas et al., 2015). The chaos narrative depicts a storyline of despair and hopelessness as all hopes of a future worth living are lost (Frank, 2013). At this point in his story, Gareth was sharing some of his darker moments following SCI that resonated with chaos and the dangers of restitution.

At the time of his first interview, I had immersed myself with the ABR center for a period of six months. During that time I had come to enjoy participating with Gareth in ABR as he was always having a laugh and a joke on the gym floor. Many participants referred to this friendly teasing or 'banter' between them and their trainers which allowed people to laugh and joke in the face of adversity. Specifically within the narrative environment of ABR, in my field notes I documented that typical storytelling was composed of masculine banter. This form of communication revolved around trainers and participants insulting each other, telling sexual jokes, and recounting stories of past dating escapades. These acts can be part of the process by which men with SCI re-establish culturally normative masculine behavior that aligns with their post injury identity (Gerschick and Miller, 1995; Jordan et al., 2013). Therefore to effectively carry out my observational research as a female within ABR, I tried to fit in with this narrative environment and integrate myself within these ways of interacting and communicating. On the one hand I believed that partaking in banter led to my acceptance within the ABR center, and resulted in participants openly sharing their stories with me. On the other hand, initially some of these stories came as a total shock to me as they completely contrasted the stories told and performed on the gym floor:

Today was a fairly emotional day. I interviewed Gareth for the first time and I was shocked and saddened by the stories he told me. Gareth is such a typical Jack-the-lad on 
the gym floor. He is constantly making jokes, teasing me and having a laugh with everyone. There is never a serious moment with Gareth around. But this all changed when Gareth agreed to be interviewed today. Gone was the comical lad. Instead I was privileged to listen to some of Gareth's most heart wrenching moments following his SCI. He openly talked to me about his experiences in hospital, problems within the care home, issues of inaccessibility in his own home and some of his most distressing times. Gareth said that if he didn't have that hope that he will get better, that he wouldn't want to carry on. I actually had a tear in my eye when I reflected on this interview. (Reflexive journal)

As this example highlighted, my role as an assistant trainer, and my position as an 'insider', elicited the telling of stories in interviews that were silenced on the gym floor. Yet in becoming an insider, I began to hold preconceptions about ABR and the people in it (Thorpe \& Olive, 2016). When interviewing Gareth, my comment about his positive attitude to ABR only served to illustrate my assumptions about his positive outlook on life due to our previous interactions on the gym floor. These assumptions meant that I was initially unprepared, shocked and upset to hear stories that made reference to chaos. Qualitative researchers are encouraged to be empathetic with participants whilst maintaining a sense of professional detachment (Sparkes \& Smith, 2014). Yet as Day and Martinelli (2016) caution, it is not uncommon for researchers to experience an unexpected emotional response. Furthermore, as noted by Sanders et al. (2017), if left unmanaged, this shock and distress may also have a negative impact upon relationships with participants and future data collection. In line with the recommendations of these authors, I drew upon my reflexive journal to openly share my emotions, and discussed any further issues with trusted others.

Over time, the stories that Gareth told about his experiences of ABR, and hopes he held for the future, focused less upon walking again and more upon activities perceived to improve his quality of life. This change reflected a shift in narrative from exercise is restitution towards 
exercise is medicine. The exercise is medicine narrative provides an alternative story to restitution whereby participating in exercise is aimed at improving health and well-being without the promise of walking again (Papathomas et al., 2015). This is not to say that Gareth abandoned the restitution narrative and gave up on the hope of a cure in the future. Rather, concrete hopes of recovery from SCI through ABR were replaced with more realistic hopes of a better future with SCI. This change in hope was bought about by small increases in the function of his upper limbs which made significant improvements to both his independence and mental health. During his second interview, it was the use of the timelining (Figure 1) that facilitated these reflections and provided insights into relationships between health, well-being and hope at different contours of time (Brockmeier, 2000; Sheridan et al., 2011). For example, Gareth discussed his experiences through historical time (since the onset of SCI), cyclical time (the negative impact of Christmas) and future time (looking forward to moving house):

Gareth: My mental health would mostly follow my physical health (on the timeline). Except at Christmas, that's when it would drop a bit. I haven't got myself around dealing with Christmas very well at the moment. Then although my physical health decreased recently, my mental health didn't, as I had got over something. The pneumonia was really bad and getting over that made me feel stronger really. Toni: Are you still up here (very good mental health) now?

Gareth: Yes I'm still up there. This Christmas might be different for me because the new house is coming on so it will be nearly moving time. It is just going to make so much difference; it is getting more and more exciting because I can see light at the end of the tunnel... The main thing is I now realize that I'm in this for the long run, it's not a short fix kind of thing... With my right arm I can move it around a lot now and I've got a little mechanical arm that goes on it. I can work my iPad and that was it now so I can play on eBay and go online which I couldn't do before. It's just little bits of muscle that I have 
got that they work on but it makes a hell of a difference. But it's more in mind I think as well, it makes me feel better, it's a good feeling. Mentally wise it's good as well.

Toni: What goals are you working towards at ABR?

Gareth: Just the drinking side of things, being able to lift the cup up to have a cup of tea... The other goal I have now is trying to get this right arm stronger because on people's birthday, especially my wife's birthday, Valentines and Christmas, I want to be able to write in the card. ( $2^{\text {nd }}$ interview)

As Gareth's story revealed, despite positive increases in physical health, his mental health and hope were routinely negatively impacted at Christmas time. Yet in the last year, overcoming serious illness resulted in a huge boost in his perceived mental health and changed his hopes towards a more positive future. This change was reflected by the exercise is medicine narrative shifting to the forefront of his story, while restitution remained in the background. As Papathomas et al. (2015) contend, the exercise is medicine and exercise is restitution narratives can co-exist for those who hope for a cure from SCI, but do not have total faith in it. This position whereby people hope for an outcome such as cure from SCI, yet realistically expect that a cure is unlikely, relates to the paradox of chronic illness. In this paradox, people "defy limitations in order to realise greater life possibilities and... accept limitations in order to avoid enervating struggles with immutable constraints" (Barnard, 1995, p.39). For Soundy et al. (2013), this represents hope in possibility where people are prepared to accept that what is hoped for may not occur. This hope in possibility is central to the paradox "as it simultaneously incorporates the apparently contradictory positions of acknowledgement (which is an essential component of adjustment and leads towards acceptance), and allows the patient to have a defiant attitude" (Soundy et al., 2014, p.258). Thus, drawing upon the two narratives can represent a healthier psychological scenario that may better support long term physical activity participation (Papathomas et al., 2015).

<Insert Figure 1 here> 


\section{Robert's story}

Robert was 46 years old when he had a motorbike accident leaving him paraplegic with a T5-T6 complete SCI. He was four years post injury at the time of our first interview and had been attending $\mathrm{ABR}$ two to three times a week for two and a half years. Robert's story of ABR across time was dominated by the exercise is medicine narrative as he was continually motivated to be physically active to improve his health and well-being and reduce the ailments associated with SCI:

Well I've had with my diet, a two stone weight loss and psychologically it's helped me a lot. It's something in my life, whereas I have a lot of lonely boring days. Yeah takes my mind off things, because when I have loads of time on my hands and not doing anything, I'm inactive. I think of the accident and my life in general and it's kind of depressing. So this has helped me psychologically because I was on anti-depressants and I've come off them now. I was on a load of medication, pain medication and what not, and I've come off that as well so that's since I've been doing this. It's been good for me because I didn't like the fact of all the medication I was on anyway, it was horrifying me. You know it was a great thing to get off that, so now it's very minimal now the medication I have to have... but when I did come here initially I had pain medication, bladder and bowel and some other important things. But a lot of those issues have been addressed now since I've been doing this, I feel a lot better. ( $1^{\text {st }}$ interview)

Robert's story highlights some of the secondary health conditions and decreased mental health associated with inactivity after SCI (Martin Ginis et al., 2012). He told a story of increased weight gain and subsequent depression following his accident. However, through regular exercise, Robert was able to reduce his weight and manage other conditions including bladder and bowel issues. Therefore for Robert, exercise at ABR was literally a form of medicine (Malcom, in-press), as it was perceived by him to be more effective in improving his mental health in comparison to prescribed medication. As a consequence of his improved 
physical and psychological state, he was able to stop taking medication for pain and depression completely. This positive relationship between exercise, health and well-being was also reflected in the stories told by Robert's trainers:

Louise: When Robert first came here I remember him he was on medication. It just zonked him out, he just wasn't with it, he just didn't want to talk to anyone, he was closed down sort of thing and it was quite sad. He was probably the most not with it and completely disconnected with his body person that I've probably seen. Then you see him now and he chats to everyone, he's coming out with cheeky comments all the time, you see him smiling. I know it's not much compared to somebody who is very happy and outgoing, but for him I can massively see that change. People like Robert are here for maintenance. He makes it clear he doesn't think he's going to get any better and that he just wants to keep his muscle and his bones fit and healthy.

In addition to improving health and well-being, Robert was driven to exercise regularly throughout his time at ABR to address functional goals such as improving his balance and mastering the floor to chair transfer. These goals were in line with the traditional functional goals of SCI rehabilitation perceived by physiotherapists to promote independence (Williams, 2016). Furthermore, these goals aligned with realistic hopes and expectations of ABR concerning ongoing aliment relief and long term health and illness prevention as dictated by the exercise is medicine narrative (Papathomas et al., 2015). As such, those who buy into and live their lives by the exercise is medicine narrative can develop a powerful long-term commitment to living an active lifestyle as there is no fixed endpoint goal. In other words, the hopes associated with the exercise is medicine narrative echo those of the quest narrative; transcendent hopes for a better, healthier future (Smith \& Sparkes, 2005; Soundy et al., 2013). The quest narrative offers transcendent hope which embraces the unknown and provides a narrative scaffold that allows the teller to flexibly adapt to an uncertain future (Frank, 2013; Smith \& Sparkes, 2005). The exercise is medicine narrative could therefore be more beneficial, and more 
valued by physiotherapists in SCI rehabilitation, in promoting a physically active lifestyle through ABR.

On the surface Robert's story appeared to be an exemplar of the exercise is medicine narrative. Yet despite these improvements in physical and mental health reported by both Robert and his trainer Louise, when Robert completed the timeline in his second interview he revealed another side to his story (Figure 2). When plotting his physical and mental health, Robert revealed that he did not consider himself to be of 'good' health. As illustrated in his timeline, Robert felt that over time his health remained poor. The onset of secondary health conditions common to SCI, such as urinary tract infections (Adriaansen et al., 2013), contributed to the fluctuations in his physical and mental health. Nonetheless, it was Robert's inability to accept his SCI that had the greatest perceived negative impact upon his mental health over time: Robert: It (mental health) started really low (on the timeline), and it got a bit better, but it's still not on the positive.

Toni: Why is that?

Robert: Psychologically I can't accept that his has happened to me and I'm in a wheelchair. I don't think I will ever accept it, I just can't. I can't relate and talk to other people in wheelchairs... Being here I've seen more people who are more severely injured than me, and can do a lot less than me, and that makes me feel guilty the way I feel because, you know. They've even said to me I do brilliant, I motorbike still and it makes me feel quite bad like, when I feel down sometimes I think "oh I can do quite a lot of stuff." It's just I don't think I ever will accept it. But I've seen a psychiatrist and a psychologist and what not, and I've got a bit of an understanding, and they say I don't ever have to accept it as long as I make the most of my life what I can. ( $2^{\text {nd }}$ interview) $<$ Insert Figure 2 here> Indeed, although the exercise is medicine narrative does negate the dangers associated with restitution, this contrasting data from Robert illustrated how it can depict an overly 
romantic story of physical activity and SCI. For Frank (2013), the quest narrative - which shares similar hopes to the exercise is medicine narrative - risks romanticizing illness and disability. The risk of quest stories is that the transformation to embracing uncertainty and transcendent hope is depicted as too clean a process. In reality, living with SCI presents many recurrent moments of risk and uncertainty; the journey has many ups and downs, good days and bad days (Charmaz, 1991; Lohne \& Severinsson, 2005). Furthermore, without concrete hopes of recovery, the exercise is medicine narrative depicts an idealistic approach to exercise (Papathomas et al., 2015). This is because transcendent hopes of a better future would suggest that people were seemingly on the road to accepting their SCI (Smith \& Sparkes, 2005; Soundy et al., 2013). However, this was not the case for Robert.

There were further aspects of ABR that illuminated this other side to Robert's story and lack of acceptance of his SCI. For example, every six months all participants at ABR took part in an evaluation. This evaluation was a test of people's functional scale and motor score that was used to document any progress made. Although documenting one's activities and physical progress can be a source of pleasure (Phoenix \& Orr, 2014), for others measuring physical ability could also be a source of displeasure. This component of documented displeasure was evident in following field note taken during a six month evaluation with Robert shortly following his second interview:

Today I witnessed my first ever evaluation. Chris, Robert's trainer, was incorporating Robert's evaluation into his normal session and I was acting as assistant, fetching equipment and assisting with transfers etc. as normal. What was most striking about this interaction was Robert's total lack of engagement in the process. Chris started with Robert's legs and went through the motions of asking him to move his toes, ankles, and knees; even though both of them knew Robert could not perform any of these movements. From a lying position, Chris then proceeded to take one leg at a time and place it in the middle of his chest. He then asked Robert to try and push against his chest whilst Chris 
resisted his efforts. In addition Chris asked Robert to think about performing this action.

Again no movement. No movement meant no progress in functional recovery in Robert's lower limbs. This continued for another half hour with Robert being asked to perform a range of movements on command, testing his core and upper body strength. All the while Robert said nothing. He just silently complied with the evaluation. (Field notes)

As suggested in my observation above, the six month evaluation could be a source of displeasure when no progress is made. This displeasure could arise from the ability of documented pleasure to connect individuals with other bodies (Phoenix \& Orr, 2014). These other bodies can include one's former body or future body, and the body of others. In Robert's case, this evaluation could have been a source of displeasure as it reminded him of his former able-bodied self and his present and future disabled self.

Taken together, this combination of interviewing, timelining and observation revealed a more complex relationship between health, well-being and hope following SCI than may have appeared through interviewing alone. This revelation from Robert forced me to reflect upon my understanding of his story as this represented a different paradoxical position on hope and acceptance that contested the idealist nature of the exercise is medicine narrative. On the one hand he exercised to improve his health and well-being, rather than in search of a cure for his SCI. Yet on the other hand, over time he remained adamant he would never accept his SCI. Therefore in this example the type of hope being drawn upon by Robert may be intransitive hope. For Frank (2013), intransitive hope has no specified object or objective, but leaves the future open. Through intransitive hope people can tell a story of exercise is medicine without having to accept their SCI, yet still hope for a life that "can be at least worthwhile and at best valuable" (Frank, 2013, p.205).

\section{Conclusions}

In this paper I have illustrated how an integrated methods approach revealed a more comprehensive understanding of the experiences of ABR for people with SCI. Drawing upon 
multiple lenses highlighted valuable insights into the relationship between health and wellbeing, and hope and acceptance that may not have been elicited from one method alone. In other words, each method contributed to an overall understanding of how narratives of SCI and ABR play out over time. For example, the time spent developing trust and rapport with participants during observation facilitated the telling of personal stories in interviews that both complemented and contrasted aspects of the stories observed on the gym floor. Furthermore, the integration of timelining revealed relationships between health, well-being, hope and acceptance over different contours of time which were not evident in observations and may not have been elicited from interviewing alone. The construction of the timeline also facilitated a deeper reflection upon life experiences over time which was hard to achieve through questioning and conversation in interviews and observation. Without a multiple methods approach, these different aspects of participants' experiences may have been overlooked. Taken together, the collection, analysis and integration of pluralistic data sets stimulated critical thinking and awareness. I was forced to reflect and question upon how I understood participants' experiences, and the assumptions of the dominant narratives the participants were drawing upon to construct their stories of ABR.

In addition, this paper has also extended the disability research in sport and exercise psychology by illustrating how narratives of SCI and ABR play out over time. The longitudinal nature of data collection highlighted the temporal dynamics of storytelling and provided a more nuanced understanding of how narratives shift over time. Collecting longitudinal data also offers another benefit in that it guards against taking a 'snapshot' into the lives and experiences of participants and recognizes that a range of variables (e.g., age, gender, time since injury, level of injury) can shape stories over time. The risk of a snapshot approach is that researchers may finalize people by reducing their stories to a single narrative type. For example, without a longitudinal approach, the shift away from exercise is restitution in Gareth's story, and the aspects of Robert's story which challenged the assumptions of the exercise is medicine 
narrative, may not have been realized. As Frank (2010, p.119) explains, "a typology of narratives recognises that experience follows from the availability of narrative resources, and people's immense creativity is in using these resources to fabricate their stories. The types in a typology are of narratives, not people”. In reality, as this study highlights, no actual story conforms exclusively to only one typology. Rather, people operate within these typologies which act as resources for telling stories and expectations when listening to stories (Frank, 2013; Smith, 2016).

Moreover, the use of multiple methods has practical value for people with SCI. Utilizing interviews, timelines and participant observations allowed participants to express themselves in a variety of complementary and congruent ways. The analysis of these pluralistic data sets into integrated meanings offered different stories of SCI and ABR over time. Sharing these stories could expand people's narrative resources by offering different perspectives on what stories of SCI and ABR might $d o$ for people (Frank, 2013; Smith et al., 2016). Furthermore, circulating different stories of SCI and ABR could have practical applications for others in SCI rehabilitation. For instance, Gareth's story might serve to alleviate some of the concerns health professionals hold with ABR centers. For Gareth, an increase in upper limb function from participating in ABR did have a positive impact on health and well-being and led to a future focus on hopes aligning with exercise is medicine as opposed to exercise is restitution. In contrast, although exercise is medicine is an idealized narrative type in SCI contexts, Robert's story challenges the notion that all stories adhering to this storyline reflect 'good' health and well-being.

In line with the health psychology literature (Burton et al., 2017; Chamberlain et al., 2011; Lyons et al., 2015; Papaloukas et al., 2017), this paper supports the use of an integrated approach to allow for a more comprehensive and enriched understanding of the complexity of sport and exercise experiences for disabled people. That said, there are a number of methodological considerations which should inform future multiple methods research with 
disabled populations. First, whilst the integration of methods offers the opportunity to conceptually advance disability sport and exercise psychology research, it should not be undertaken for innovation alone. For example, researchers within this field should draw upon multiple methods with an informed and justified methodological purpose that is consistent with the study aims and epistemological and theoretical underpinnings (Gibson et al., 2013; Papaloukas et al., 2017; Smith et al., 2015).

Second, it should not be assumed that collecting multiple forms of data will guarantee new insights and understandings of disabled peoples' sport and exercise experiences. Rather, to achieve integration of pluralistic data sets necessitates a rigorous and reflexive approach to data collection, analysis and interpretation (Chamberlain et al., 2011; Smith et al., 2015). Regardless of the methodology and/or type of data analysis employed, researchers should analyze and present the various forms of data together to ensure the fusion of separate methods into integrated meanings. In this study, the pluralistic data sources were used to inform each other rather than as a method of triangulation. Triangulation - the use of multiple data sets, methods or theories to analyze a research question - is used to establish credibility by seeking the corroboration of findings and identification of a single truth (Burke, 2016). In line with my philosophical assumptions, the contrasting and contradicting data sets forced me to reflect and question the interpretations I had made regarding participants' stories. For example, the contrasting data obtained from the interviews and observations with participants in this study were not seen as contesting 'a truth'. Rather, the multiple data sets revealed experiences, emotions and behaviors that illustrated the 'multiple truths' of SCI and ABR. Further reflections could include more detail regarding how researcher and participant demographics (e.g., age, gender, ethnicity, sexuality and/or (dis)ability) impact the research findings (Brighton and Williams, in-press; Thorpe \& Olive, 2016).

In line with the points above, the third issue concerns judging the quality of multiple methods research. By adopting a relativist approach to sport and exercise psychology research, 
the criteria drawn upon to enhance quality should be appropriate to the form of inquiry undertaken (Burke, 2016; Smith \& McGannon, 2017). For this study I drew upon a subset of criteria from the many proposed lists of criteria for judging qualitative research (e.g., Morse, 2015; Tracy, 2012) that I deemed relevant to guide the research process. For example, the worthiness of the topic was illustrated by the strong rationale for the use of multiple methods to achieve a more nuanced understanding of the experiences of ABR over time. The criteria rich rigor was sought through spending substantial time in the field to generate data that could provide meaningful and significant contributions to the disability sport and exercise psychology literature. With regard to multiple methods studies, evidence of integration (Chamberlain et al., 2011; Sparkes, 2015) was drawn upon to demonstrate meaningful coherence of the purpose, method, results and interpretations of pluralistic data sets.

Fourth, researchers could consider integrating other visual methods such as photography, paintings and drawings to generate, interpret and communicate knowledge with and to disabled people (see Phoenix \& Rich, 2016). The use of participant-generated photos in combination with interviews has been successfully employed to capture and analyze identity practices of disabled young men transitioning into adulthood (Gibson et al., 2013), understand quality of life for people with paraplegia (Burton et al., 2017) and to explore the lived experiences of chronic illness in socially or normatively marginalized groups (Papaloukas et al., 2017). Accordingly, the combination of photos and interviews can engage disabled people in the research, promote and facilitate reflection, and empower participants to lead and control the nature of the data. As Burton et al. (2017) note, the use of methods that encourage reflection may be valuable for disabled people whose reflective capacity could be reduced due to medication, symptoms or impairment.

Yet despite the wealth of benefits to be offered through multiple methods research, there are practical and ethical challenges and limitations to be considered. With visual methods in particular, the ability of the participant to take part in the research project should be taken into 
account (Papaloukas et al., 2017). In this study, some participants with higher SCI injuries which impacted their upper limb function had difficultly drawing their timeline, but still wanted to take part. Others with complete paralysis asked me to draw their timeline for them based upon their detailed descriptions of their health, well-being and hope over time. In both cases, the use of timelining was still a valuable tool in enriching my understanding of the participants' experiences of ABR. Similarly, alternative communication strategies may be necessary to enhance participation for those with intellectual impairments (Burton et al., 2017), or capture perspectives that may be challenging or intimidating to discuss face-to-face (Gibson et al., 2013). These are important issues as "restriction of research to participants for whom these approaches do not present a challenge only serves to marginalize groups who are already noticeably absent from the research" (Burton et al., 2017, p. 14). Lastly, it is crucial to note that visual methods such as timelining and photographs may not be suitable for all participants in all contexts (Phoenix \& Rich, 2016). Participants can feel vulnerable sharing intimate aspects of their lives or be upset and disturbed when being confronted with visual representations of their experiences (Papaloukas et al., 2017; Sheridan et al., 2011). With this in mind, researchers may adopt a culturally responsive relational reflexive ethical position to negotiate their desire to gain rich understandings whilst caring for their participants' well-being (Sparkes \& Smith, 2014).

In conclusion, this paper demonstrated that integrating multiple methods was successful in illuminating a nuanced understanding of participants' experiences of ABR over time. This novel combination of interviews, visual methods and participant observation may have promise for similar psychological research projects exploring the complexity of sport and exercise experiences for disabled people. Overall, epistemologically and theoretically informed multiple methods studies have the potential to conceptually advance our understanding of sport and exercise psychology in disabled contexts. It is also hoped that multiple methods studies involving disabled people - which demonstrate rigorous and reflexive integration throughout the research process - can advance other fields within sport and exercise psychology. 


\section{Funding}

This research did not receive any specific grant from funding agencies in the public,

commercial, or not-for-profit sectors.

\section{Acknowledgements}

I would like to thank the two anonymous reviewers for their critical, insightful and encouraging comments that enhanced this paper. I would also like to thank Prof. Brett Smith, Dr Anthony

Papathomas \& Prof. Andrew Sparkes for their guidance, enthusiasm and support which fostered a more critical approach to my research in disability and physical activity.

\section{References}

Adriaansen, J. J., Post, M. W., de Groot, S., van Asbeck, F. W., Stolwijk-Swüste, J. M., Tepper, M., \& Lindeman, E. (2013). Secondary health conditions in persons with spinal cord injury: a longitudinal study from one to five years post-discharge. Journal of Rehabilitation Medicine, 45(10), 16-22.

Barnard, D. (1995). Chronic illness and the dynamics of hoping. In S. K. Toombs, D. Barnard, \& R. A. Carson (Eds.), Chronic illness from experience to policy. (pp38-57). Indiana: Indiana University Press.

Brighton, J., \& Williams, T.L. (in-press). Using interviews to explore experiences of disability in sport and physical activity. In R. Medcalf \& C. Mackintosh (Eds.). Researching difference in sport and physical activity. London: Routledge.

Burke, S. (2016). Rethinking 'validity' and 'trustworthiness' in qualitative inquiry. In B. Smith \& A.C. Sparkes (Eds.). International handbook of qualitative methods in sport and exercise (pp. 330-339). London: Routledge.

Brockmeier, J. (2000). Autobiographical time. Narrative Inquiry 10(1), 51-73.

Burton, A., Hughes, M., \& Dempsey, R. C. (2017). Qualitative of life research: A case for combining photo-elicitation with interpretative phenomenological analysis. Qualitative Research in Psychology, DOI: 10.1080/14780887.2017.1322650.

Chamberlain, K., Cain, T., Sheridan, J., \& Dupuis, A. (2011). Pluralisms in qualitative research: From multiple methods to integrated methods. Qualitative Research in Psychology, 8, 151169.

Charmaz, K. (1991). Good days, bad days: The self in chronic illness and time. New Brunswick, $\mathrm{NJ}$ : Rutgers.

Creswell, J. (2011). Controversies in mixed methods research. In N. Denzin, \& Y. Lincoln (Eds.), The Sage handbook of qualitative research (4th ed., pp. 269-283). London: Sage.

Culver, D., Gilbert, W. and Sparkes, A. (2012). Qualitative research in sport psychology journals: The next decade 2000-2009 and beyond. The Sport Psychologist, 26, 261-281.

Day, M. \& Martinelli, L. (2016). The complexities of narrating athletic injuries. QMiP Bulletin, 22, 14-20.

Frank, A. W. (2010). Letting stories breathe: A socio-narratology. London: University of Chicago Press.

Frank, A. W. (2011). Practicing dialogical narrative analysis. In J. A. Holstein \& J. F. Gubrium (eds.), Varieties of narrative analysis (pp.33-52). Thousand Oaks, CA: Sage.

Frank, A. W. (2013). The wounded storyteller ( $2^{\text {nd }}$ ed.). London: University of Chicago Press. 
Gerschick, T., \& Miller, A. (1995). Coming to terms: Masculinity and physical disability. In D. Sabo, \& D. Gordon (Eds.), Men's health and illness (pp.138-204). London: Sage.

Gibson, B. E., Mistry, B., Smith, B., Yoshida, K. K., Abbott, D., Lindsay, S., \& Hamdani, Y. (2013). The integrated use of audio diaries, photography, and interviews in research with disabled young men. International Journal of Qualitative Methods, 12(1), 382-402.

Gubrium, J. F., \& Holstein, J. A. (2009). Analyzing narrative reality. London: SAGE Publications Ltd.

Hermanowicz, J. C. (2013). The longitudinal qualitative interview. Qualitative Sociology, 36, 189-208.

Jones, M. L., Evans, N., Tefertiller, C., Backus, D., Sweatman, M., Tansey, K., \& Morrison, S. (2014). Activity-based therapy for recovery of walking in chronic spinal cord injury: Results from a secondary analysis to determine responsiveness to therapy. Archives of Physical Medicine and Rehabilitation, 95(12), 2247-2252.

Jordan, M. M., Berkowitz, D., Hannold, E., Velozo, C. A., \& Behrman, A. L. (2013). Thinking through every step: How people with spinal cord injuries relearn to walk. Qualitative Health Research, 23(8), 1027-1041.

Kolar, K., Ahmad, F., Chan, L., \& Erickson, P. G. (2015). Timeline mapping in qualitative interviews: A study of resilience with marginalized groups. International Journal of Qualitative Methods, 14(3), 13-32.

Lohne, V., \& Severinsson, E. (2005). Patients' experiences of hope and suffering during the first year following acute spinal cord injury. Journal of Clinical Nursing, 14(3), 285-293.

Lyons, A. C., Goodwin, I., McCreanor, T., \& Griffin, C. (2015). Social networking and young adults' drinking practices: Innovative qualitative methods for health behavior research. Health Psychology, 34(4), 293-302.

Malcom, D. (in-press). Is exercise medicine? A critical sociological examination. In J. Piggin, L. Mansfield \& M. Weed (Eds.). Routledge handbook of PA, policy and practice. London: Routledge.

Martin Ginis, K. A., Jörgensen, S., \& Stapleton, J. (2012). Exercise and sport for persons with spinal cord injury. $P M \& R, 4(11), 894-900$.

Martin Ginis, K. A., Ma, J. K., Latimer-Cheung, A. E., \& Rimmer, J. (2016). A systematic review of review articles addressing factors related to physical activity participation among children and adults with physical disabilities. Health Psychology Review, 10, 478-494.

McCaughey, E. J., Purcell, M., McLean, A. N., Fraser, M. H., Bewick, A., Borotkanics, R. J., \& Allan, D. B. (2016). Changing demographics of spinal cord injury over a 20-year period: A longitudinal population-based study in Scotland. Spinal Cord, 54, 270-276.

McGannon, K., \& Schweinbenz, A. (2011). Traversing the qualitative-quantitative divide using mixed methods: some reflections and reconciliations for sport and exercise psychology. Qualitative Research in Sport, Exercise and Health, 3, 370-384.

Morse, J. M. (2015). Critical analysis of strategies for determining rigor in qualitative inquiry. Qualitative Health Research, 25, 1212-1222.

O’Reilly, K. (2012). Ethnographic methods, (2 ${ }^{\text {nd }}$ ed.). Abingdon: Routledge.

Papaloukas, P., Quincey, K., \& Williamson, I. R. (2017). Venturing into the visual voice: Combining photos and interviews in phenomenological inquiry around marginalisation and chronic illness. Qualitative Research in Psychology, DOI: 10.1080/14780887.2017.1329364.

Papathomas, A. (2016). Narrative inquiry: From cardinal to marginal... and back? In B. Smith \& A.C. Sparkes (Eds.). International handbook of qualitative methods in sport and exercise (pp. 37-48). London: Routledge.

Papathomas, A., Williams, T. L., \& Smith, B. (2015). Understanding physical activity participation in spinal cord injured populations: Three narrative types for consideration. 
International Journal of Qualitative Studies on Health and Well-being. DOI: 10.3402/qhw.v10.27295.

Perrier, M-J., Smith, B., \& Latimer-Cheung, A. E. (2013). Narrative environments and the capacity of disability narratives to motivate leisure-time physical activity among individuals with spinal cord injury. Disability and Rehabilitation 35(24), 2089-2096.

Phoenix, C., \& Orr, N. (2014). Pleasure: A forgotten dimension of physical activity in older age. Social Science \& Medicine, 115, 94-102.

Phoenix, C. \& Rich, E. (2016). Visual methods research. In B. Smith \& A.C. Sparkes (Eds.). International handbook of qualitative methods in sport and exercise (pp. 139-151). London: Routledge.

Quel de Oliveira, C., Refshauge, K, Middleton, J., de Jong, L., \& Davis, G. M. (2017). Effects of activity-based therapy interventions on mobility, independence, and quality of life for people with spinal cord injuries: A systematic review and meta-analysis. Journal of Neurotrauma, 34(9), 1726-1743.

Richardson, E. V., Smith, B., \& Papathomas, A. (2017). Disability and the gym: Experiences, barriers and facilitators of gym use for individuals with physical disabilities. Disability and Rehabilitation, 39(19), 1950-1957.

Riessman, C.K. (2008). Narrative methods for the human sciences. Thousand Oaks, CA: Sage.

Sadowsky, C. L., \& McDonald, J. W. (2009). Activity-based restorative therapies: Concepts and applications in spinal cord injury-related neurorehabilitation. Developmental Disabilities Research Reviews, 15, 112-116.

Sanders, P., Wadey, R., Day, M., \& Winter, S. (2017). Qualitative fieldwork in medical contexts: Confessions of a neophyte researcher. Qualitative Research in Sport, Exercise and Health, DOI: 10.1080/2159676X.2017.1351390.

Sheridan, J., Chamberlain, K., \& Dupuis, A. (2011). Timelining: Visualizing experience. Qualitative Research, 11(5), 552-569.

Smith, B. \& McGannon, K. R. (2017). Developing rigor in qualitative research: Problems and opportunities within sport and exercise psychology. International Review of Sport and Exercise Psychology, DOI: 10.1080/1750984X.2017.1317357.

Smith, B. (2013). Disability, sport and men's narratives of health: A qualitative study. Health Psychology, 32(1), 110-119.

Smith, B. (2016). Narrative analysis. In E. Lyons \& A. Coyle (eds.), Analysing qualitative data in psychology ( $2^{\text {nd }}$ ed., pp. 202-221). London: Sage.

Smith, B., \& Sparkes, A. C. (2005). Men, sport, spinal cord injury and narratives of hope. Social Science \& Medicine, 61(5), 1095-1105.

Smith, B., Bundon, A., \& Best, M. (2016). Disability sport and activism identities: A qualitative study of narratives of activism among elite athletes' with impairment. Psychology of Sport and Exercise, 26, 139-148.

Smith, B., Caddick, N., \& Williams, T. L. (2015). Qualitative methods and conceptual advances in sport psychology. In S.D. Mellalieu \& S. Hanton (Eds.). Contemporary advances in sport psychology: A review (pp. 202-225). London: Routledge.

Soundy, A., Sayers, J., Stubbs, B., \& Roskell, C. (2014). Don't take my hope away: Understanding the patient's hope in neurological rehabilitation. International Journal of Therapy and Rehabilitation, 21(6), 257-256.

Soundy, A., Smith, B., Butler, M., Lowe, C. M., Dawes, H., \& Winward, C. H. (2010). A qualitative study in neurological physiotherapy and hope: Beyond physical improvement. Physiotherapy Theory and Practice, 26(2), 79-88.

Soundy, A., Smith, B., Dawes, H., Pall, H., Gimbrere, K., \& Ramsay, J. (2013). Patient's expressions of hope and illness in three neurological conditions: A meta-ethnography. Health Psychology Review, 7(2), 177-201. 
Sparkes, A. C. (2015). Developing mixed methods research in sport and exercise psychology: Critical reflections on five points of controversy. Psychology of Sport and Exercise, 16, 4959.

Sparkes, A. C., \& Smith, B. (2014). Qualitative research methods in sport, exercise \& health. From process to product. London: Routledge.

Thomas, C. (2014). Disability and impairment. In J. Swain, S. French, C. Barnes, \& C. Thomas (Eds.), Disabling barriers - enabling environments (3rd ed., pp. 9-16). London: Sage.

Thorpe, H. \& Olive, R. (2016). Conducting observations in sport and exercise settings. In B. Smith, \& A. C. Sparkes (Eds.), Routledge handbook of qualitative research in sport and exercise (pp.124-138). London: Routledge.

Tracy, S. J. (2010). Qualitative quality: eight "big-tent" criteria for excellent qualitative research. Qualitative Inquiry, 16, 837-851.

van Lit, A., \& Kayes, N. (2014). A narrative review of hope after spinal cord injury: Implications for physiotherapy. New Zealand Journal of Physiotherapy, 42(1), 33-41.

Williams, T. L., Smith, B., \& Papathomas, A. (2014). The barriers, benefits and facilitators of leisure time physical activity among people with spinal cord injury: A meta-synthesis of qualitative findings. Health Psychology Review, 8, 404-425.

Williams, T. L., Smith, B., \& Papathomas, A. (2016). Physical activity promotion for people with spinal cord injury: Physiotherapists' beliefs and actions. Disability \& Rehabilitation. DOI: 10.1080/09638288.2016.1242176.

Wolcott, H. F. (2005). The art of fieldwork ( ${ }^{\text {nd }}$ ed.). Lanham, MD: AltaMira Press.

World Health Organization. (2017). Spinal Cord Injury. http://www.who.int/mediacentre/factsheets/fs384/en/. [accessed 01 July 2017]. 


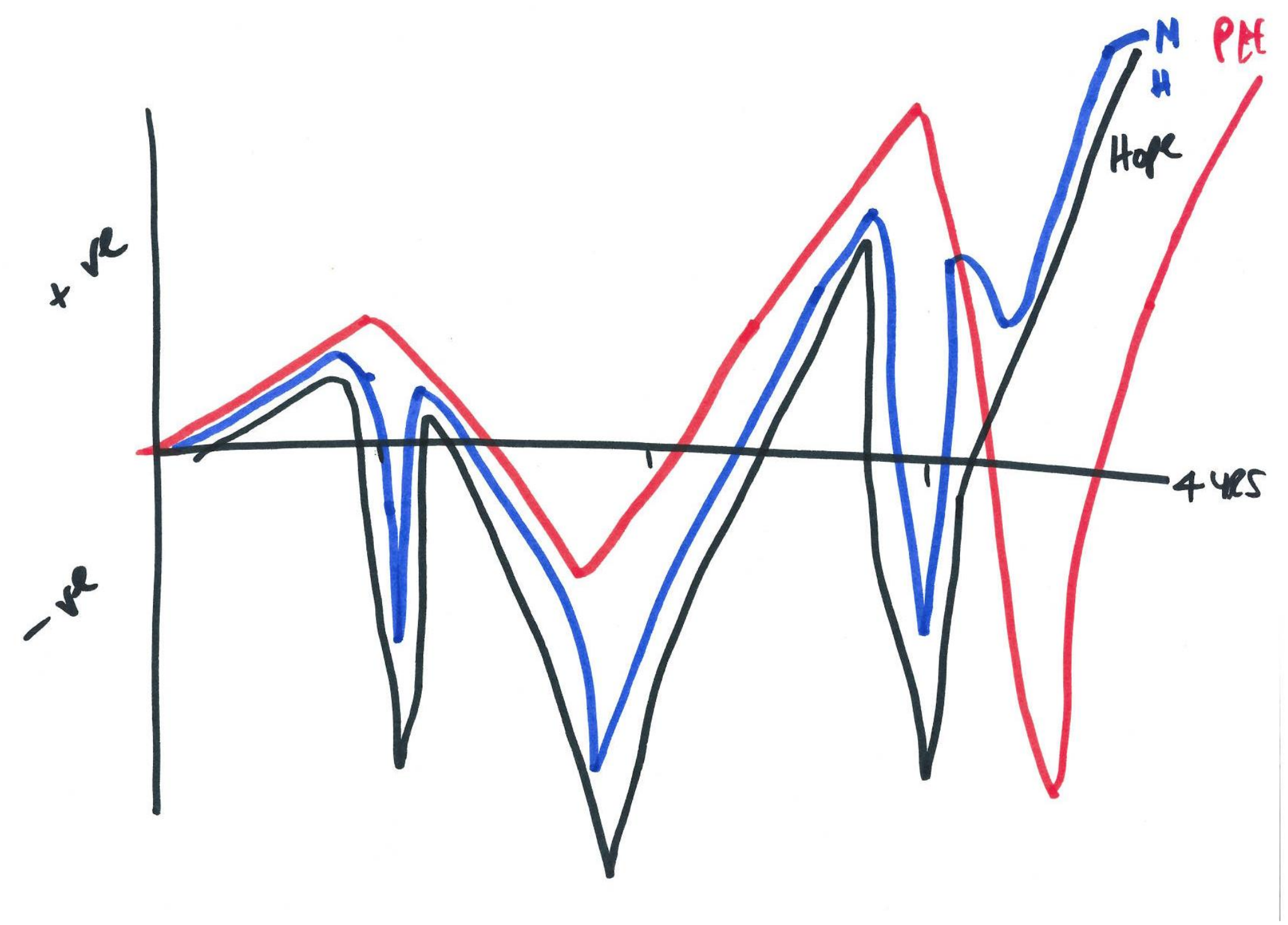

Figure 1: Gareth's timeline 


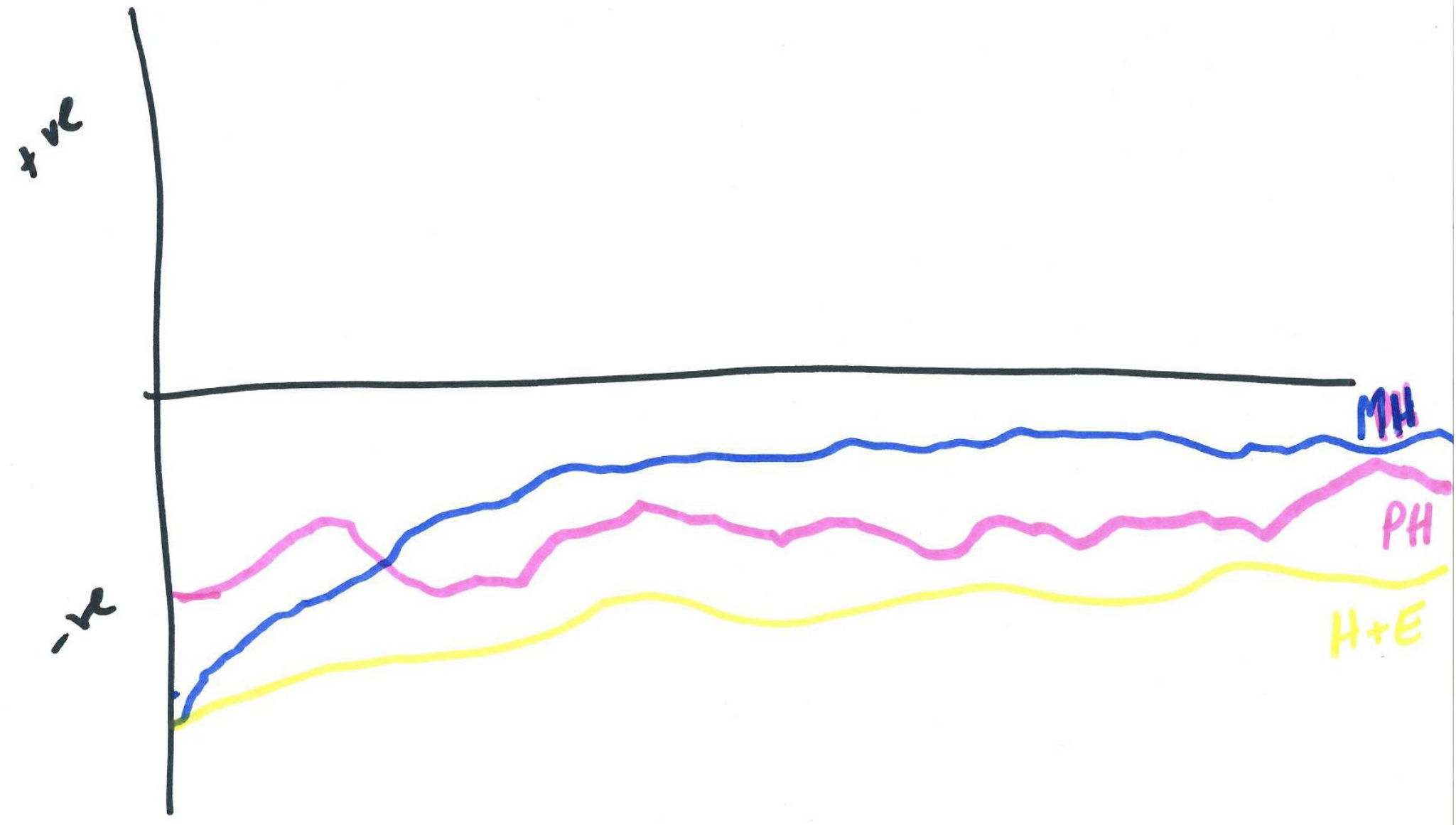

Figure 2: Robert's timeline 